\title{
Eighth International Congress of Entomology
}

The eighth International Congress of Entomology will be held in Stockholm, Sweden, August 8-15, 1948. The fact that all steamship sailings are currently booked to capacity for months in advance makes it seem necessary for those expecting to attend the congress in 1948 to arrange for passage as early as possible. Steamship companies have not issued sailing lists for 1948, but expect to do so in the early fall. A number of lines have listed sailings for the present season, among them, the Cunard, French, Belgian, Swedish, Norwegian, Gdynia (Polish), Holland-American, etc., the first mentioned expecting soon to have two new steamers in service. It is understood that the Thirteenth International Congress of Zoology will be held in Paris some time in July, 1948, and it is hoped that all entomologists going to Stockholm will plan to attend the Zoological Congress also in order that the interests of the entomologists may be fully represented before the more comprehensive body. Should a sufficient number of individuals indicate that they expect to sail about mid-June, it may be feasible to engage passage on the same steamer. Early information as to the probable number of participants is especially desired in order that the housing committee in Stockholm may make the necessary arrangements. The undersigned, as member of the executive committee, would appreciate it if he be kept informed as early as possible as to plans of those expecting to attend the sessions.-O. A. JoHANnsen, Comstock Hall, C. U., Ithaca, N. Y. June, 1947. 

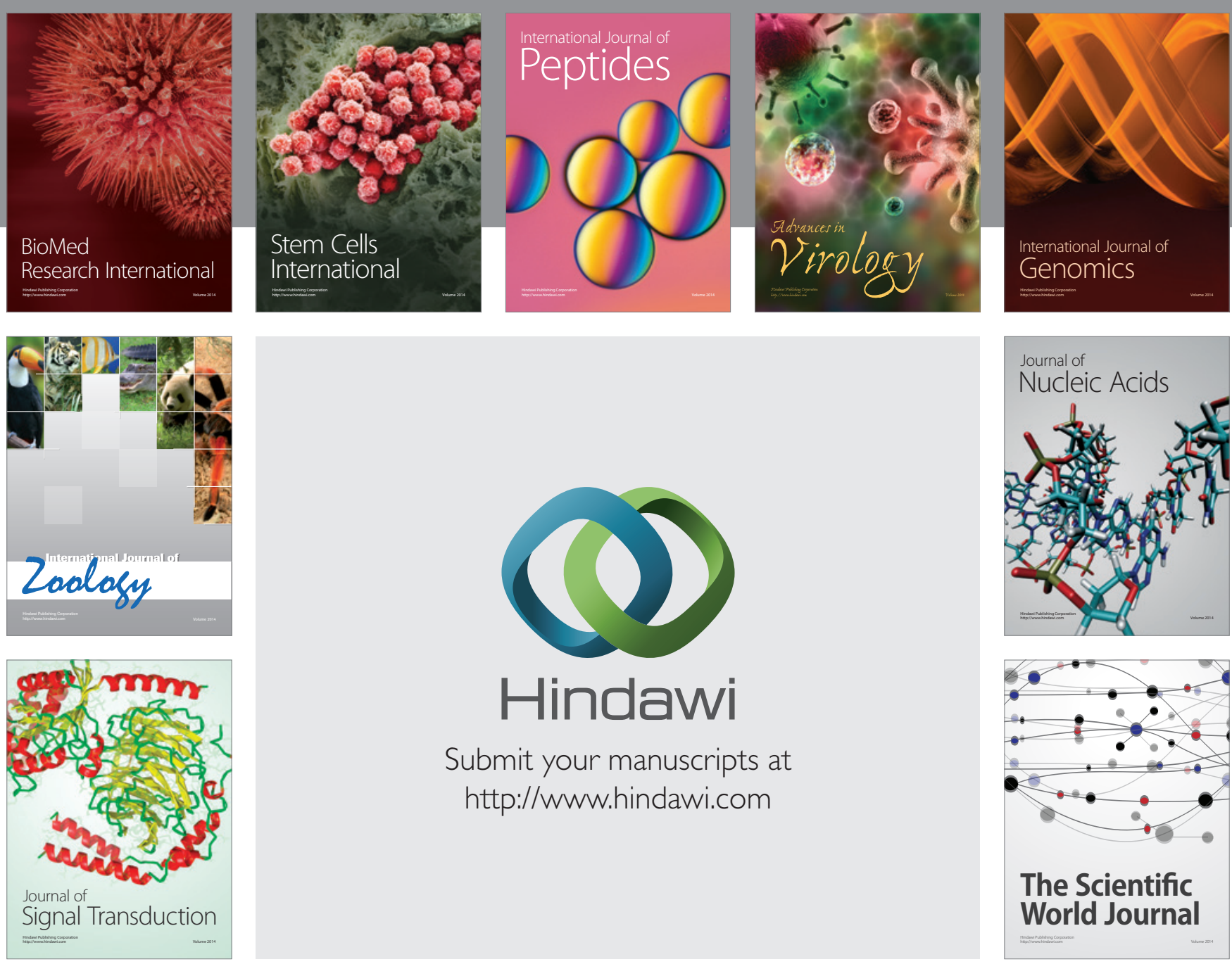

Submit your manuscripts at

http://www.hindawi.com
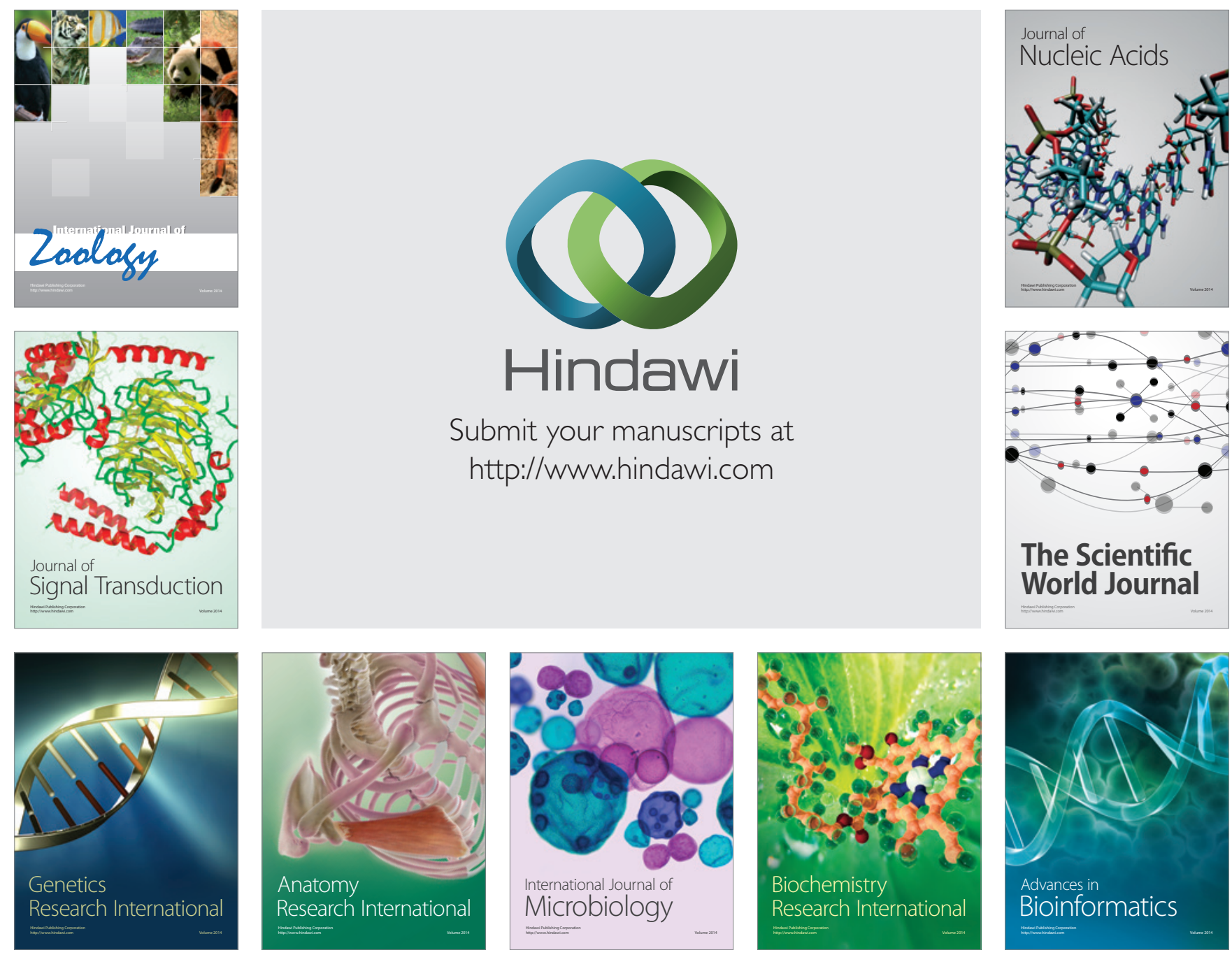

The Scientific World Journal
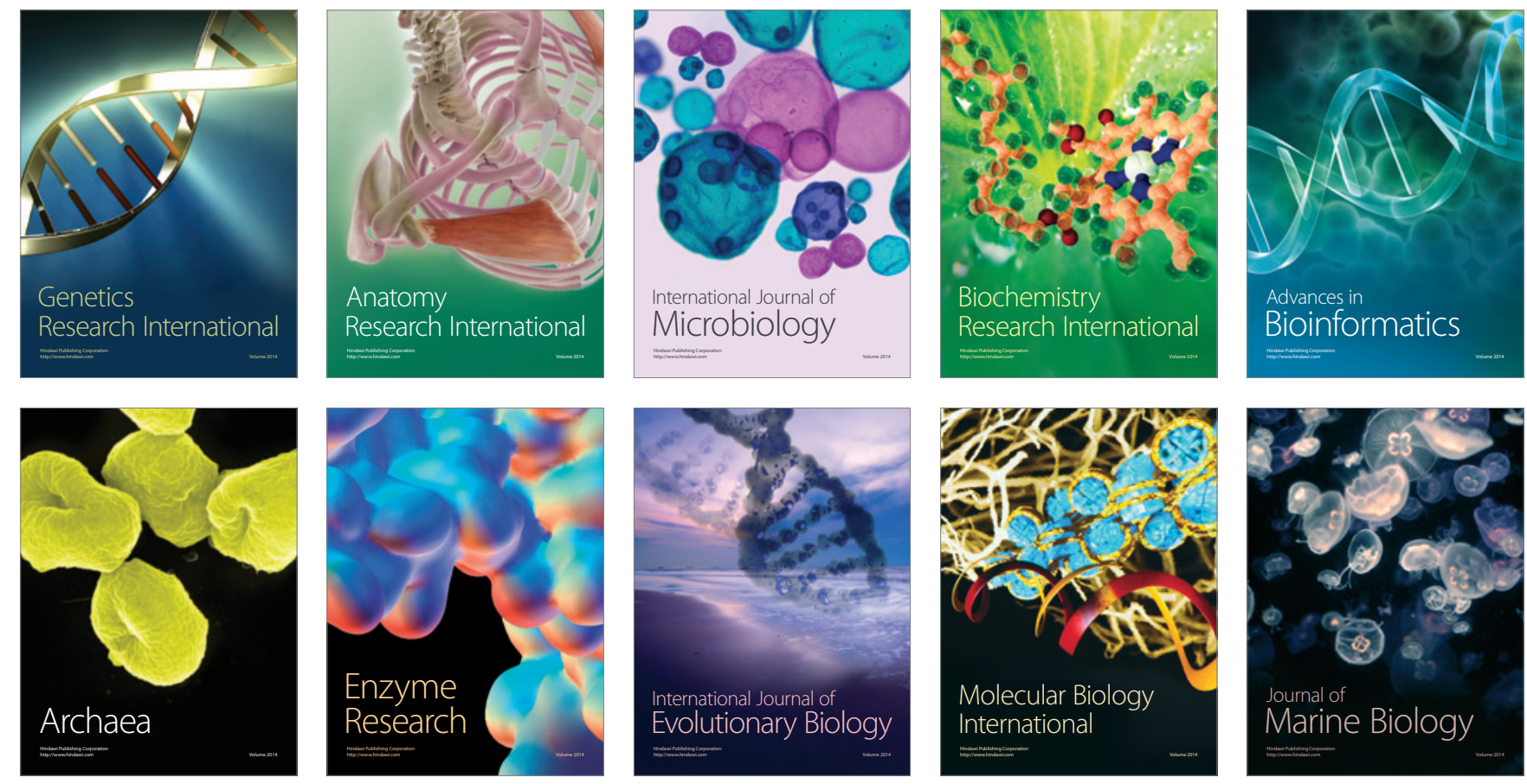